\title{
Effects of a carbonic anhydrase inhibitor on cerebral blood flow in geriatric patients
}

\author{
D. J. WYPER, C. J. McALPINE, K. JAWAD, AND B. JENNETT \\ From the MRC Cerebral Circulation Research Group, Institute of Neurological Sciences, \\ Southern General Hospital, Glasgow, and the Department of Geriatric Medicine, \\ Royal Alexandra Infirmary, Paisley
}

SYNOPSIS A carbonic anhydrase inhibitor (UK-12,130) was shown to increase cerebral blood flow in mildly demented geriatric patients. Oral administration caused a significant increase in blood flow at two different dose levels; this persisted for at least six weeks, which was the duration of the longest study. There was no consistent improvement in mentation during treatment. Blood flow was measured by the washout of ${ }^{133} \mathrm{Xe}$ after inhalation of this inert gas.

Carbonic anhydrase inhibitors (CAI) have been investigated for their vasodilatory effect because it seemed likely that vessels might react in the same way as they do to increases in $\mathrm{PaCO}_{2}$. Carbonic anhydrase catalyses the reversible hydration of $\mathrm{CO}_{2}$ in erythrocytes and in the glial cells in choroid plexus, but not in the neurones of the brain (Maren, 1967); this would be expected to result in changes in the extracellular $\mathrm{pH}$ in the brain with resultant cerebral vasodilatation. One such CAI drug, acetazolamide (Diamox) can increase cerebral blood flow (CBF) by as much as inhalation of $5 \% \mathrm{CO}_{2}$ (Ehrenreich et al., 1961) both in experimental animals (Severinghaus and Lassen, 1967; Lassen, 1968; Cotev et al., 1968; Kong et al., 1969) and in patients suffering from cerebrovascular disease (Posner and Plum, 1960; Ehrenreich et al., 1961; Gotoh et al., 1966). At effective doses, however, other tissues containing carbonic anhydrase are also affected (Maren, 1963), and a marked diuresis occurs because of the renal effect (Maren, 1967). A recently produced CAI (UK-12,130) has a more selective action on the brain, because it crosses the bloodbrain barrier more readily it is more lipophilic and has lower ionization compared with acetazolamide. At doses producing a similar increase in $\mathrm{CBF}$ in dogs the diuresis was four times less

(Accepted 26 April 1976.) than with acetazolamide. The only study in man showed a significant increase in CBF after intravenous dosage, using the intracarotid injection of radioactive xenon to measure the CBF (Skinhøj, 1975). This invasive method has limited application and it is difficult to justify repeated measurements. We have therefore used the recently developed inhalation method to make repeated measurements of CBF before and during oral administration of UK-12,130 in demented geriatric patients-a group for whom the drug has been recommended as of possible therapeutic benefit.

\section{METHOD}

Seven mildly demented but cooperative female patients aged 67 to 91 years were chosen at the Department of Geriatric Medicine, Royal Alexandra Infirmary, and consent for their inclusion in the trial obtained in writing from relatives. They were brought by car to the Institute of Neurological Sciences, Southern General Hospital, Glasgow at weekly intervals for measurements.

Three separate dosage regimens were employed:

Regimen 1 Initial loading dose of $100 \mathrm{mg} \mathrm{UK}-12$, 130. This was followed (four hours later) by $50 \mathrm{mg}$ three times daily. This dosage was continued for two weeks.

Regimen 2 Initial loading dose of $100 \mathrm{mg} \mathrm{UK}-12$, 130. This was followed four hours later by $25 \mathrm{mg}$ three times daily. This dosage was continued for two weeks. 
Regimen 3 Initial loading dose of $100 \mathrm{mg}$, followed four hours later by $50 \mathrm{mg}$ three times daily for six weeks.

All doses were taken orally.

A minimum of four weeks elapsed between the end of one course and the start of another. The purpose of regimen 3 was to investigate possible escape from the effects of the drug.

There were six patients in regimen 1 , five of these plus one new patient in regimen 2 , and four in regimen 3 .

MEASUREMENT OF CEREBRAL BLOOD FLOW Cerebral blood flow was measured using the two-minute slope ${ }^{133} \mathrm{Xe}$ inhalation technique (Wyper et al., 1976). The patient, who was sitting or lying on a couch, breathed through a rubber mouthpiece. Once a steady respiratory pattern had been obtained, a 32-second count of background radioactivity was recorded; then the two-minute saturation phase began, during which a mixture of ${ }^{133} \mathrm{Xe}$ in air at a concentration of $1 \mathrm{mCi} / \mathrm{l}$. was inhaled. Clearance of ${ }^{133} \mathrm{Xe}$ from the head was then recorded for $2 \frac{1}{2}$ minutes, during air breathing using four $2.5 \mathrm{~cm}(1 \mathrm{in})$ diameter collimated scintillation detectors. Two detectors were positioned to view the hemispheres from front to back and the other two were positioned on the left side viewing the temporal and parietal regions. The end-expired air concentration of ${ }^{133} \mathrm{Xe}$ was also recorded using a welltype scintillation counter, in order to allow a correction to be made for recirculating xenon. The end-tidal $\mathrm{PCO}_{2}$ was measured using an infra-red $\mathrm{CO}_{2}$ analyser.

CBF measurements were made as follows:

Regimen 1 Two measurements before the loading dose then two hours and four hours after the loading dose. One measurement after one week on the regular dosage immediately before that day's first dose. One measurement two hours after this. One measurement after a further week on the regular dose immediately before that day's first dose repeated two hours after this.

Regimen 2 Measurements as in regimen 1.

Regimen 3 One measurement before the loading dose of $100 \mathrm{mg}$. One measurement after two weeks on a regular dosage of $50 \mathrm{mg}$ three times daily. One measurement after a further four weeks on the same dosage.

\section{RESULTS}

No significant regional variations were encountered in CBF between different detectors; the $C B F$ values presented are the averages for the four detectors.
1. Before starting the treatment in these patients the average $\mathrm{CBF}$ was $31.3 \pm 2.3 \mathrm{ml} /$ $100 \mathrm{~g} / \mathrm{min}$ compared with $50.1 \pm 7.0 \mathrm{ml} / 100 \mathrm{~g}$ /min for a group of 29 normal subjects aged 20 to 50 years; both were at a similar, normal level of $\mathrm{PCO}_{2}$.

2. As two control measurements of CBF were made on each patient (Tables 1 and 2 ) the precision of the technique when applied to this particular group of patients can be assessed. If the distribution of the values of the difference between the first and second measurements is assumed to be Gaussian (not a critical assumption as the range of $\mathrm{CBF}$ values is small), the standard deviation of this distribution gives a measure of the precision of the technique. Any two measurements of CBF must differ by twice this standard deviation to be significantly different at the $\mathrm{P}<0.05$ confidence level.

T A B L E 1

CBF/PCO: FOR 50 MG THRICE DAILY STUDY*

\begin{tabular}{|c|c|c|c|c|c|c|}
\hline & & \multicolumn{2}{|c|}{ Patient } & \multirow[b]{2}{*}{$F M C D$} & \multirow[b]{2}{*}{$E R$} \\
\hline & $J F$ & $S R$ & $E M c M$ & $F M$ & & \\
\hline \multirow[t]{2}{*}{ Control } & $30 / 40$ & $33 / 29$ & $32 / 36$ & $37 / 40$ & $31 / 32$ & $36 / 36$ \\
\hline & $27 / 40$ & $28 / 29$ & $30 / 34$ & $31 / 40$ & $27 / 32$ & $32 / 36$ \\
\hline \multirow{4}{*}{$\begin{array}{l}2 \mathrm{~h} \\
4 \mathrm{~h} \\
1 \text { weck }\end{array}$} & $31 / 39$ & $33 / 29$ & $27 / 35$ & $33 / 40$ & $29 / 32$ & $29 / 35$ \\
\hline & $23 / 40$ & $33 / 29$ & $29 / 35$ & $32 / 36$ & $26 / 30$ & $32 / 35$ \\
\hline & $40 / 31$ & $34 / 22$ & $37 / 36$ & $44 / 31$ & $33 / 29$ & $54 / 26$ \\
\hline & $40 / 29$ & $40 / 22$ & $34 / 30$ & $46 / 32$ & $33 / 29$ & $54 / 25$ \\
\hline \multirow[t]{2}{*}{2 weeks } & $42 / 29$ & $36 / 21$ & $38 / 29$ & $41 / 34$ & $35 / 31$ & $48 / 26$ \\
\hline & $34 / 27$ & $39 / 20$ & $45 / 30$ & $40 / 32$ & $36 / 28$ & $46 / 25$ \\
\hline
\end{tabular}

* $\mathrm{CBF}$ in $\mathrm{ml} / \mathrm{100g} / \mathrm{min}$ and end-tidal $\mathrm{PCO}_{2}$ in $\mathrm{mmHg}$.

T A B L E 2

$\mathrm{CBF} / \mathrm{PCO}_{2}$ FOR 25 MG THRICE DAILY STUDY*

\begin{tabular}{|c|c|c|c|c|c|c|}
\hline & \multicolumn{6}{|c|}{ Patient } \\
\hline & $E M C M$ & $E R$ & $F M c D$ & $F M$ & $A D$ & $S R$ \\
\hline & -- & - & $\cdots \quad \cdots$ & 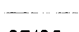 & & \\
\hline \multirow{2}{*}{ Control } & $34 / 33$ & $31 / 37$ & $26 / 38$ & $37 / 35$ & $44 / 37$ & $35 / 31$ \\
\hline & $30 / 38$ & $26 / 38$ & $28 / 39$ & $37 / 35$ & $44 / 37$ & $35 / 31$ \\
\hline $2 \mathrm{~h}$ & $42 / 37$ & $39 / 38$ & $28 / 36$ & $36 / 34$ & $43 / 34$ & $28 / 30$ \\
\hline $4 \mathrm{~h}$ & $35 / 35$ & $34 / 35$ & $33 / 35$ & $41 / 35$ & $43 / 35$ & $37 / 29$ \\
\hline \multirow[t]{2}{*}{1 weck } & $40 / 32$ & $41 / 31$ & $36 / 30$ & $43 / 32$ & $46 / 36$ & $33 / 24$ \\
\hline & $36 / 32$ & $41 / 31$ & $37 / 29$ & $40 / 32$ & $50 / 32$ & $31 / 24$ \\
\hline \multirow[t]{2}{*}{2 weeks } & $32 / 23$ & $43 / 21$ & $30 / 20$ & $45 / 29$ & $43 / 36$ & $42 / 25$ \\
\hline & $32 / 32$ & $43 / 31$ & $34 / 29$ & $45 / 29$ & $45 / 33$ & $37 / 23$ \\
\hline
\end{tabular}

*CBF in $\mathrm{ml} / 100 \mathrm{~g} / \mathrm{min}$ and end-tidal $\mathrm{PCO}$ in $\mathrm{mmHg}$. 
Analysed in this way, the precision of the technique is $\pm 5 \mathrm{ml} / 100 \mathrm{~g} / \mathrm{min}$ or $16 \%$ (twice the standard deviation of the differences between control measurements).

3. REGIMEN $150 \mathrm{mg}$ three times daily (Table 1). Cerebral blood flow was not significantly increased two or four hours after the initial oral dose, but after a week CBF was found to have increased by $31.5 \pm 6.4 \%$ (mean and standard error); after a second week CBF was still significantly above the pre-treatment level $(28.6 \pm 2.9 \%)$ (Fig. 1a). For each patient, the average CBF increase after one and two weeks is statistically significant on an individual basis $(\mathrm{P}<0.05$ as described above $)$.

End-tidal $\mathrm{PCO}_{2}$ was not significantly changed two or four hours after the loading dose but was reduced after one and two weeks by $18.7 \pm 3.7 \%$ and $19.0 \pm 4.3 \%$ respectively (Fig. $1 b$ ).

4. REGIMEN $225 \mathrm{mg}$ three times daily (Table 2). After the initial loading dose the increases in CBF were $12.6 \pm 9.6 \%$ at two hours (not significant because of the scatter of results) and $11.2 \pm 3.7 \%$ at four hours $(\mathrm{P}<0.05)$ (Fig. 1a). After one and two weeks the increases in CBF were $19.5 \pm 7.9 \%$ and $19.3 \pm 8.2 \%$ respectively, compared with the control values $(\mathrm{P}<0.05)$.

Although these increases were lower than the corresponding values for the $50 \mathrm{mg}$ thrice daily study, this was not significant on a statistical basis because of large individual differences of the five subjects common to regimens 1 and 2 ; two responded equally to the $25 \mathrm{mg}$ thrice daily dose as to the $50 \mathrm{mg}$ thrice daily dose.

End-tidal $\mathrm{PCO}_{2}$ did not change significantly after two hours but fell by $6.7 \pm 1.4 \%$ after four hours $(P<0.02)$, by $16.2 \pm 2.3 \%$ after one week $(\mathrm{P}<0.002)$, and $17.3 \pm 2.9 \%$ after two weeks $(P<0.002)$.

5. REGIMEN 3 Six week study. The increase in CBF two weeks after starting on a regular $50 \mathrm{mg}$ three times daily dosage was $25.0 \pm 6.8 \%$. After an additional four weeks CBF was $21.5 \pm$ $4.3 \%$ above control (Fig. 2a). There was no significant difference between the values of two weeks and six weeks (Table 3).

TA B LE 3

CBF/PCO, FOR SIX WEEK STUDY*

\begin{tabular}{lcccc}
\hline & \multicolumn{3}{c}{ Patient } \\
& $F M$ & $F M C D$ & $E R$ & $S R$ \\
\hline Control & $33 / 40$ & $29 / 37$ & $30 / 37$ & $32 / 26$ \\
2 weeks & $44 / 29$ & $33 / 25$ & $42 / 32$ & $36 / 24$ \\
6 weeks & $44 / 26$ & $34 / 27$ & $37 / 26$ & $36 / 22$ \\
\hline
\end{tabular}

${ }^{*} \mathrm{CBF}$ in $\mathrm{ml} / 100 \mathrm{~g} / \mathrm{min}$ and end-tidal $\mathrm{PCO}_{2}$ in $\mathrm{mmHg}$.

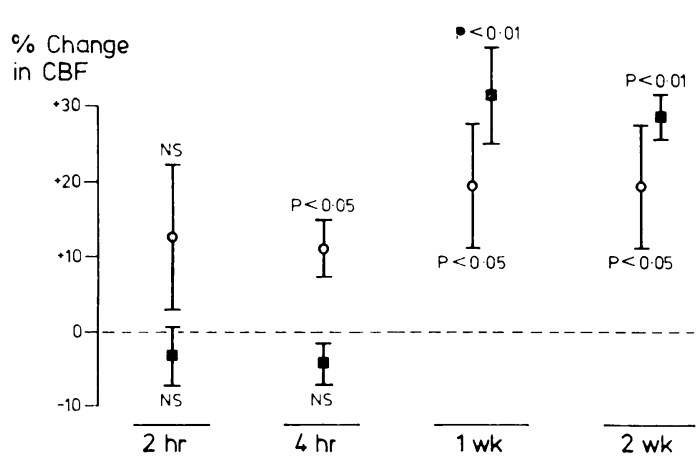

(a)
$\%$ Change

in $\mathrm{P}_{\mathrm{et}} \mathrm{CO}_{2}$

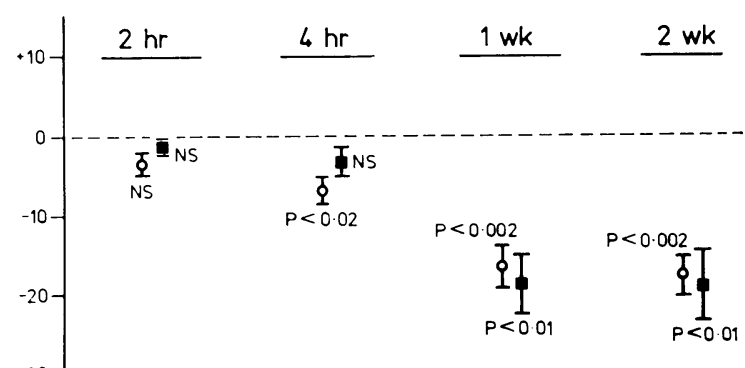

(b)

FIG. 1 (a) Cerebral blood flow (CBF) and (b) end-tidal $\mathrm{PCO}_{2}\left(\mathrm{PetCO}_{2}\right)$ as a percentage of control for regimen 1 (50 mg thrice daily dosage) $\square$, and regimen $2(25 \mathrm{mg}$ thrice daily dosage $) \bigcirc$. Error bars indicate standard error of mean of six measurements. 


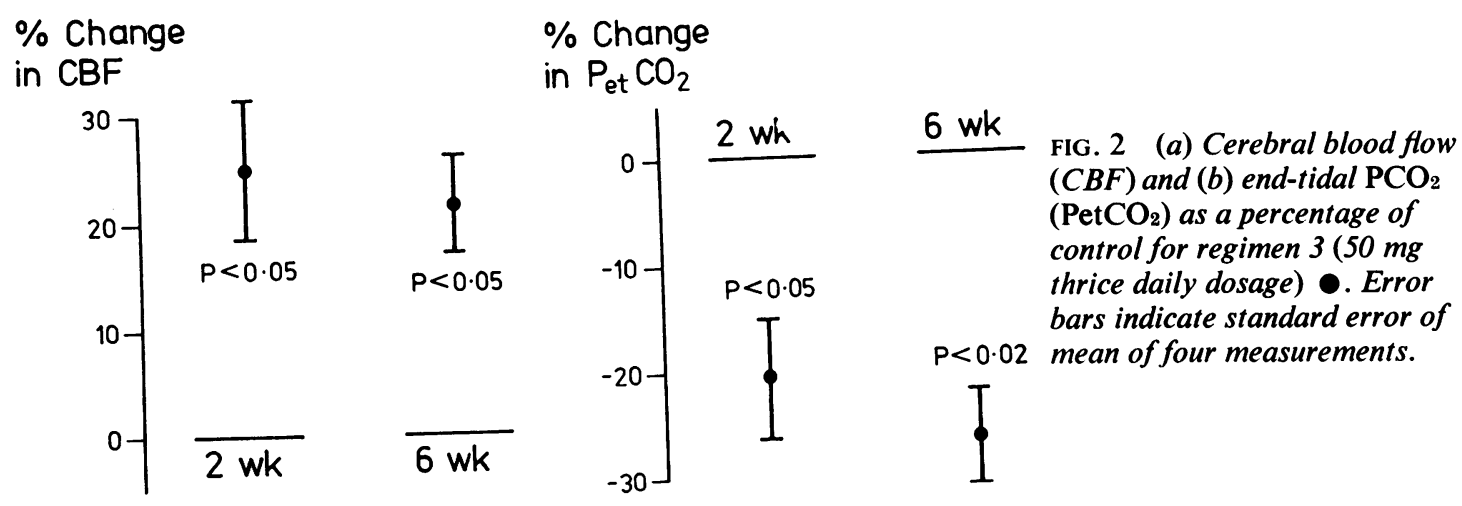

(a)

(b)

End-tidal $\mathrm{PCO}_{2}$ fell by $20.5 \pm 5.7 \%$ and $26.7 \pm 4.3 \%$ after two and six weeks respectively (Fig. 2b).

\section{DISCUSSION}

This study shows that a significant and persisting increase in the cerebral blood flow occurs after the oral administration of UK-12,130. Repeatability studies indicate that these changes would not be expected in these patients if they did not receive a drug. There was no consistent improvement in mentation associated with the increase in cerebral blood flow.

Increases found in $\mathrm{CBF}$ tended to be accompanied by decreases in end-tidal $\mathrm{PCO}_{2}$, but as these were attributed to the effect of the drug it was not considered appropriate to apply corrections to the CBF values to compensate for changes in $\mathrm{PCO}_{2}$. When erythrocyte carbonic anhydrase is inhibited the normal criteria for measuring blood and end-tidal $\mathrm{PCO}_{2}$ do not apply. In the presence of CAI the normally rapid hydration of $\mathrm{CO}_{2}$ (at the tissue capillary) and its dehydration (at the alveolar capillary) is incomplete, resulting in an increased gradient of $\mathrm{CO}_{2}$ from tissue to alveolus, since $\mathrm{CO}_{2}$ cannot reach equilibrium with $\mathrm{H}_{2} \mathrm{CO}_{3}$ (Maren, 1967). Thus, tissue and capillary $\mathrm{PCO}_{2}$ and arterial $\mathrm{H}_{2} \mathrm{CO}_{3}$ will rise and alveolar $\mathrm{PCO}_{2}$ falls.

An increase in CBF was observed four hours after the loading dose of UK-12,130 in the second study, but not in the first. This can be explained by the high affinity of the erythrocyte for UK-12,130. It can be shown that after the first loading dose of $100 \mathrm{mg}$ approximately $70 \%$ of the UK-12,130 is bound by the erythrocyte carbonic anhydrase, and about $20 \%$ is bound to plasma proteins and is not available for enzyme inhibition. Thus the plasma concentration, which reflects the availability to other tissues including brain, is very low. Data from young normal volunteers showed that after $100 \mathrm{mg}$ of UK-12,130, plasma levels were undetectable, whereas erythrocyte levels were $20-30 \mu \mathrm{g} / \mathrm{ml}$.

The clearance of UK-12,130 from the erythrocyte is slow ( $\mathrm{T} \frac{1}{2} \bumpeq$ two months) whereas from plasma $T \frac{1}{2}$ is approximately 12 hours. The second study began between four and seven weeks after the first two week treatment of $50 \mathrm{mg}$ three times daily and so there would be little drug in plasma but between $50 \%$ and $75 \%$ of the maximum concentration in erythrocyte. Administration of $100 \mathrm{mg}$ UK-12,130 under these conditions would saturate the remaining erythrocyte binding sites and leave a significant amount of the drug in plasma. Consistent with this was the finding that administration of a second dose of UK-12,130 to the normal volunteers, one week after the first, produced significant plasma levels $(0.5 \mu \mathrm{g} / \mathrm{ml})$.

The persistent high level of CBF after six weeks in regimen 3 indicates that there is no significant tolerance effect. 


\section{CONCLUSIONS}

UK-12,130 produces a significant increase in cerebral blood flow in demented geriatric patients which is persistent over some weeks.

It was found that it was practicable to use the inhalation method of measuring blood flow in this group of patients. It promises to be of value in other investigations calling for repeated measurements over a period of time, and in patients in whom invasive methods would not be justified.

We should like to thank Pfizer Central Research, Sandwich, for supplies of UK-12,130 and for data about the pharmacology.

\section{REFERENCES}

Cotev, S., Lee. J., and Severinghaus, J. W. (1968). The effects of acetazolamide on cerebral blood flow and cerebral $\mathrm{pO}_{2}$. Anaesthesiology, 29, 471-477.

Ehrenreich, D. L., Burns, R. A., Alman, R. W., Fazekas, J. F. (1961). Influence of acetazolamide on cerebral blood flow. Archives of Neurology (Chic.), 5, 125-130.

Gotoh, F., Meyer, J. S., and Tomita, M. (1966). Carbonic anhydrase inhibition and cerebral venous blood gases and ions in man. Archives of Internal Medicine, 117, 39-46.

Kong, Y., Lunzer, S., Heyman, A., Thompson, H. K., and Saltzman, H. A. (1969). Effects of acetazolamide on cerebral blood flow of dogs during hyperbaric oxygenation. American Heart Journal, 78, 229-237.

Lassen, N. A. (1968). Brain extracellular pH: The main factor controlling cerebral blood flow. Scandinavian Journal of Laboratory and Clinical Investigation, 22, 247-251.

Maren, T. H. (1963). The relationship between enzyme inhibition and physiological response in the carbonic anhydrase system. Journal of Pharmacology and Experimental Therapy, 139, 140-153.

Maren, T. H. (1967). Carbonic anhydrase: chemistry, physiology and inhibition. Physiological Review, 47, 595-781.

Posner, J. B., and Plum, F. (1960). The toxic effects of carbon dioxide and acetazolamide in hepatic encephalopathy. Journal of Clinical Investigation, 39, 1246-1258.

Severinghaus, J. W., and Lassen, N. A. (1967). Step hypocapnia to separate arterial from tissue $\mathrm{pCO}_{2}$ in the regulation of cerebral blood flow. Circulation Research, 20, 272-278.

Skinhøj, E. (1975). The effect of a new carbonic anhydrase inhibitor upon CBF and $\mathrm{CMRO}_{2}$. In Blood Flow and Metabolism in the Brain. Proceedings of the 7th International Symposium on Cerebral Blood Flow and Metabolism, pp. 11, 7-8. Edited by A. M. Harper, B. Jennett, D. Miller, and J. Rowan. Churchill Livingstone: Edinburgh.

Wyper, D. J., Lennox, G. A., and Rowan, J. O. (1976). The two minute slope inhalation technique for cerebral blood flow measurement in man. I-method, IIclinical appraisal. Journal of Neurology, Neurosurgery, and Psychiatry, 39, 141-146 and 147-151. 